\title{
Da Psicanálise como uma ciência particular do singular
}

\section{Of Psychoanalysis as a particular science of singular}

\section{Del Psicoanálisis como ciencia particular de lo singular}

\section{Wanderley Magno de Carvalho*}

Universidade Federal de Minas Gerais - UFMG, Belo Horizonte, Minas Gerais, Brasil

\begin{abstract}
RESUMO
O artigo propõe considerarmos a psicanálise como uma ciência do singular; diferencia ciência do cientificismo contemporâneo, e define os termos "particular", "ciência", e "singular". Em seguida, discute a concepção dominante de ciência e aplica, em oposição ao termo, assim unívoco, parte da teoria matemática dos conjuntos, apresentada pelo filósofo Alain Badiou. Propõe o reconhecimento da pluralidade das ciências, da qual infere que a psicanálise é uma ciência particular. Em seguida, aponta algumas passagens das obras de S. Freud e de J. Lacan que nos autorizam o entendimento da Psicanálise como uma ciência. Discute o tema da verdade na Psicanálise e em Badiou, e finaliza com a proposta de que o dispositivo do "passe" seja um procedimento de formalização da ciência psicanalítica.
\end{abstract}

Palavras-chave: Psicanálise, ciência, teoria dos conjuntos, singular.

\begin{abstract}
The article proposes to consider psychoanalysis as a science of the singular. It differentiates science of contemporary scientism, and defines the terms "particular", "science" and "singular". Then, it discusses the dominant conception of science and applies, in opposition to this univocal term, part of mathematical set theory presented by philosopher Alain Badiou. It proposes to recognize the plurality of the sciences, which infers that psychoanalysis is a particular science. Thereafter, it point some passages from the works of S. Freud and Lacan authorizing our understanding of psychoanalysis as a science. Discusses the theme of truth in psychoanalysis and Badiou, and ends with the proposal that the device "pass" is a procedure of formalization of psychoanalytic science.
\end{abstract}

Keywords: psychoanalysis, science, set theory, singular.

\section{RESUMEN}

El artículo tiene como propuesta considerar el psicoanálisis como ciencia de lo singular. Distingue la ciencia del cientificismo contemporáneo y define los términos: "particular", "ciencia" y "singular". A continuación se analiza la concepción dominante de la ciencia y se aplica, en oposición a su único concepto, parte de la teoría matemática de conjuntos presentados por el filósofo Alain Badiou. Propone reconocer la pluralidad de las ciencias, lo que deduce que el psicoanálisis es una ciencia e 
$\mathrm{n}$ particular. A continuación se señalan algunos pasajes de la obra de S. Freud y J. Lacan que autorizan nuestra comprensión del psicoanálisis como ciencia. Discute el tema de la verdad en el psicoanálisis de Badiou y termina con la propuesta de que el dispositivo de "pase" es un procedimiento de formalización de la ciencia psicoanalítica.

Palabras clave: el psicoanálisis, la ciencia, la teoría de conjuntos, singular.

\section{A Situação atual: neurociências, cientificismo e Psicanálise}

O sujeito é a cada vez convocado como pensamento

num ponto do procedimento em que o universal se constitui.

(Badiou, A., 2008, Oito teses sobre o universal, p. 41)

Chamaremos de cientificismo o uso comercial, propagandístico e ideológico que os donos do capital próprio, do capital de terceiros e do capital financeirizado 1 , fazem das pesquisas, dos avanços, das invenções e das descobertas das ciências com o objetivo de auferirem a cada vez, mais lucros.

O cientificismo diferencia-se das práticas científicas mesmas. É o que Brousse (2013) assinala distinguindo as ciências da utilização positivista de seus resultados. Essa utilização que ela chama de "discurso positivista" é o uso dos diversos saberes científicos "pelo discurso do mestre, de tal forma que o saber vem ocupar o lugar do significante mestre" (Brousse, 2013, p. 68).

Assim, embora os pesquisadores em neurociências sejam sérios e cuidadosos em seu trabalho, o problema que se coloca não está vinculado às suas práticas, mas às manipulações delas, ou seja, às manipulações, induções e generalizações que permitem aos financiadores e gestores dos resultados da pesquisa científica, bem como a seus publicitários, tornarem os resultados das pesquisas, uma moeda de troca, um discurso de propaganda, um ideal de comportamento a ser seguido etc.

Apresentando teorias e pesquisas explicativas sobre os chamados "transtornos mentais", os livros de psiquiatria (Sadock \& Sadock, 2007; Ey, Bernard \& Brisset, 1988; Ajuriaguerra, 1983) continuam afirmando a importância de fatores biológicos, psicológicos e sociais como causadores dos transtornos, acentuando, porém, cada vez mais, a importância dos fatores biológicos. E para tal posicionamento, tem concorrido em larga escala, o avanço das chamadas neurociências (neurobiologia, neuropsicologia, neuropsiquiatria).

A psiquiatria e as neurociências valem-se da matemática aplicada aos avanços tecnológicos da área computacional, que permitem a criação de máquinas sofisticadas usadas na investigação e visualização dos processos orgânicos envolvidos em estados psicopatológicos (exames de ressonância, de neuroimagem etc). A matemática é aplicada também à epidemiologia como se observa na coleta de 
dados que fazem os autores e colaboradores das diversas edições do Manual Diagnóstico e Estatístico dos Transtornos Mentais (DSM) da Associação Americana de Psiquiatria. Em ambos os casos, e para fundamentar essas práticas cientificas, faz-se o uso do cálculo matemático.

Les fondements de la science appliquée impliquent, d'un côté, les modèles, c'est-à-dire les équations qui décrivent les phénomènes, et, par um autre côté, lês algorithmes, c'està-dire les procédures pour résoudre les problèmes de nature arithmétique ou combinatoire, qui sont essentiellement des méthodes de calcul. (Focchi, 2011, p. 91).

Sabe-se que o uso desses métodos não é integralmente fiel à realidade, mas que eles operam com a ideia de aproximação. Nas operações que a ciência realiza com as matemáticas "la seule condition est que la réalité objectivée soit identifique à elle-même, soit la réalité dont les différences qualitatives sont réduites à l'indifférent quantitatif" (Focchi, 2011, p. 92). Não há espaço para singularidades. E a aplicação do cálculo servirá para a identificação e intervenções no organismo, pensadas principalmente em termos de neurotransmissores. Os níveis excessivos de dopamina presentes no cérebro explicarão as esquizofrenias, enquanto os níveis escassos de serotonina serão apontados como a causa das depressões. Deste modo, abre-se caminho para o aumento da medicalização e o progressivo abandono da Psicanálise e das psicoterapias.

É uma nova realidade, com a qual a Psicanálise tem de se haver. E não será um posicionamento válido, se ela o fizer apenas com a crítica, ou com o apontamento de supostos enganos dessas novas ciências.

Sendo as neurociências e as práticas que delas se valem, ancoradas na matemática aplicada e nos princípios do método científico dominante - método que inclui como critérios a universalidade, a generalização e a padronização de procedimentos técnicos - como a Psicanálise poderá constituir-se uma alternativa consistente, já que sua clínica é a do "caso a caso"? A clínica psicanalítica afirma-se como uma prática científica?

A posição de Milner (1996) é clara: a Psicanálise deverá encontrar "em si mesma os fundamentos de seus princípios e métodos" ( $p$. 31). Assim como ele, G. Iannini (2007) observa ser necessário que a Psicanálise "possa estabelecer parâmetros internos, a partir da própria esfera da racionalidade que ela instala".

Talvez seja a busca e a explicitação desses "parâmetros internos" e dos "princípios e métodos próprios" da Psicanálise, o que esteja faltando a um posicionamento consistente da mesma, frente às comunidades científicas. 


\section{Definindo os termos}

Particular e singular são categorias necessárias ao entendimento daquilo sobre o quê discorreremos. Em Lalande (1993) o particular é o "oposto ao universal" (p. 797).

Para Abbagnano (2007) o particular é o "que é uma parte ou pertence a uma parte. A proposição particular foi definida por Aristóteles da maneira seguinte: 'Chamo de particular a proposição que expressa a inerência a alguma coisa, ou a não inerência a cada coisa" (p. 745).

Tomaremos como particular o conjunto das "ciências", termo este que pede uma definição, ainda que provisória.

Definiremos as ciências como o conjunto das práticas reguladas, refletidas e exercitadas através de diferentes e rigorosos métodos, submissíveis a críticas internas e externas, e cada qual com diferentes objetos, que visam responder a problemas postos para a humanidade (local ou globalmente), bem como a inventar práticas e artefatos os quais, por um lado, respondem a esses problemas e, por outro, potencializam as habilidades humanas. Responder a um problema inicia-se com a tradução do mesmo no enunciado de um problema científico, formalizado nos termos próprios da ciência que o toma como tal.

As ciências existem como: 1) expressão linguística num texto ou numa fala; 2) modo investigativo de um pesquisador pensar, 3) como o que de verdadeiro se produziu ao cabo de suas investigações, 4) como o conjunto de saberes, acabados e acumulados, de cada uma ciência; 4) como consequência material do que seus praticantes realizam (livros, eventos científicos, práticas de ensino, produtos e artefatos decorrentes das pesquisas); e, 5) como objetos de uso dos cientificistas, para usos não científicos.

O corpus teórico e teórico-técnico de cada ciência se constitui através dos pensamentos lógico e matemático, não necessariamente explicitados por seus pesquisadores.

Quanto ao pensamento lógico, os pesquisadores/cientistas tanto poderão valer-se da lógica clássica, como também das novas lógicas tais como lógica trivalente, lógicas fuzzy, modais, paraconsistentes etc (Cunha, 2004), as quais, Haack (2002) entende como as respostas dadas às pressões para mudar a lógica clássica, já que haveria nela uma "aparente inadequação (...) para representar os vários tipos de argumento informal" (p. 208).

Quanto às matemáticas, os cientistas utilizam-se de uma ou mais das grandes áreas que as compõem (álgebra, aritmética, geometria, geometria analítica, estatística, teoria dos conjuntos) para engendrar seus raciocínios. Elas são "aplicadas" às outras ciências 
e frequentemente convocadas a legitimarem-nas. Reconhecese o papel fundamental das matemáticas no desenvolvimento do raciocínio científico. Como o escreve A. Badiou (1996), a matemática é a "ciência do ser-enquanto-ser" ( $p .13$ ), o que não significa declarar "que o ser é matemático, isto é, composto de objetividades matemáticas" (p. 16), mas sim, que as matemáticas "escrevem aquilo, que do próprio ser, é pronunciável no campo de uma teoria pura do Múltiplo." (p. 14). O múltiplo, em Badiou, é como o ser se apresenta.

O conjunto das ciências é o que, em Alain Badiou (1991), constitui uma das quatro condições de produção das verdades: o matema, o poema, a invenção política e o amor. Essas condições ele as nomeia textualmente como "procedimentos genéricos", os quais são os procedimentos que "especificam e classificam (...) todos os procedimentos suscetíveis de produzir verdades (só há verdade científica, artística, política ou amorosa)." (Badiou, 1991, p. 9).

Mas para que uma verdade se dê a partir de um procedimento genérico, há que ocorrer um evento. $E$ um evento é o que suplementa uma situação (um estado qualquer de coisas), trazendo algo inédito a ela. Porém ele não é "nem nomeável nem representável pelos recursos da situação (...). Ele é inscrito por uma nomeação singular, quando entra em jogo um significante a mais" (Badiou, 1991, p. 10). Ele é singular na situação a que pertence: "De fato, se fosse normal, e pudesse, portanto, ser representado, o evento seria uma parte da situação" (Badiou, 1996, p. 149).

Assim, toda ciência visa produzir verdades, rompendo com os saberes já criados e normalizados em uma situação. Mas, se as artes, a política e o amor também podem fazê-lo, então, como diferenciar as ciências desses outros procedimentos? Na Meditação 31 de seu "O ser e o evento" (1996), Badiou nos apresenta cinco aspectos que compõem e/ou caracterizam os quatro procedimentos de verdade: seus operadores, sua produção, as relações de interesse envolvidas, as investigações que os procedimentos fazem, e a indicação do que pode ser o próprio evento de cada procedimento. Desses cinco aspectos, três diferenciam os procedimentos genéricos.

Se na política, o evento são as "cesuras históricas em que é convocado o vazio do social na falta do Estado" (Badiou, 1996, p. 269), no amor o evento é o encontro amoroso. Na arte, os eventos são as grandes mutações estéticas, e nas ciências, as grandes mutações conceituais.

Quanto a interesses: no amor, a verdade interessa apenas aos indivíduos que estão amando. "Chamo-a de individual porque ela não interessa a ninguém, salvo os indivíduos concernidos" (Badiou, 1996, p. 268). Na política ela interessa ao coletivo, ou melhor, o coletivo se interessa por si mesmo, enquanto na ciência e na arte, o coletivo se interessa pelas transmissões e efeitos das produções. 
E, última diferença, as investigações ${ }^{2}$. Na política elas são as atividades militantes organizadas; no amor são os "episódios existenciais que o par amoroso vincula expressamente ao amor" (Badiou, 1996, p. 268). Na arte, as investigações são as próprias obras, e nas ciências elas são as invenções.

Assim, definimos provisoriamente, o conjunto das ciências. Nenhum outro conjunto de práticas humanas visa, se constitui, se localiza, se diferencia e se define conforme o acima exposto. Passemos agora ao conceito de "singular".

$\mathrm{Na}$ introdução que faz ao estudo das categorias de Aristóteles, traduzida por Boécio sob o título de 'Isagoge', Porfírio de Tiro dá uma definição de indivíduo como "entidade singular e irrepetível" (Ferrater Mora, 1994, p.1808). Na Idade Média, encontramos em Pedro Hispano, uma definição de indivíduo que se aproxima da definição de um singular: "Indivíduo é aquilo de que se diz uma única coisa, como Sócrates e Platão" (Abbagnano, 1998, p. 555).

Segundo Abbagnano (1998), também na Idade Média, São Tomás de Aquino falava de um indivíduo vago, correspondente à individualidade da espécie, e de um indivíduo único, cujo sentido é apenas próximo do que pensamos como singular e que mais adiante apresentaremos. Para Tomás de Aquino "o indivíduo único significa algo determinado, que distingue; assim o nome Sócrates significa este corpo e este rosto" (Abbagnano, 1998, p.555).

Há na filosofia moderna, segundo Ferrater Mora (1994), uma tendência a se considerar 0 indivíduo como algo singular, confundindo-se os dois termos: "A plena identificação entre individualidade e singularidade é afirmada por Wolff, ao dizer que o indivíduo como ente singular é aquele ente que se acha completamente determinado" (p. 1809).

Podemos ver que tanto em São Tomás de Aquino quanto em Wolff, o indivíduo é determinado (e até, completamente determinado), incapaz, portanto, de ser agente em qualquer sentido. Mas algo diferente se anuncia ainda na modernidade e com a contemporaneidade. Pois como nos informa Lalande (s/d):

O termo singular não representa propriamente um conceito [...]. Para passar da última espécie (species infima) à noção singular, o que se acrescenta é um princípio de individuação, que já não é uma característica ou uma soma de características, mas uma presença, uma realização sui generis (p. 655).

Abbagnano (1998) nos informa que a lógica contemporânea "considera singular o termo cuja conotação impede sua aplicação a mais de uma coisa real" (p. 485). 
E Badiou (2008) distingue "singular" de "particular" na seguinte formulação: "Chamar-se-á particular o que é identificável no saber pelos predicados descritivos. Já aquilo que, identificável como procedimento em andamento numa situação, subtrai-se a toda descrição predicativa, dir-se-á singular" (p. 42).

Mas o quê como "procedimento em andamento numa situação", poderá ser referido sem que se o inclua ou que se o identifique a um significante do saber já estabelecido? Ainda mais se considerarmos com França Neto (2009), que "o singular não clama pela inclusão, pela submissão à hegemonia".

Parece-nos inevitável reconhecer que estamos falando de algo situado fora do campo da consciência. Algo que, inconsciente e com tudo o que comporta de desejo e de gozo, move cada humano no que ele traz de único, de singular, e impedido de ser aplicado "a mais de uma coisa real". Inconsciente, que é o campo de trabalho da Psicanálise. Daí nossa hipótese: a Psicanálise é uma ciência particular do singular.

\section{Ciências e verdades}

No mundo contemporâneo, um modo específico de se fazer ciência com fins de se obter verdades veio se aperfeiçoando e se tornando tão comum, que se tornou hegemônico e quase o único a ser aceito como válido ou propriamente científico: o método lógico-experimental associado ao método hipotético-dedutivo. "A perspectiva dominante pode ser definida como "lógico-experimental", expressando séculos de prática relativamente exitosa" (Demo, 2011, p. 10).

O que caracteriza o método lógico-experimental é apresentarse ordenado, bem argumentado, formalizar-se analítica e matematicamente, e "espelhar-se na realidade empírica, girando em torno de dados mensuráveis, comprováveis e retestáveis" (Demo, 2011, p. 10).

A teoria do método hipotético-dedutivo, cujo maior defensor é Karl Popper (1994), propõe que todo pesquisador inicia seu trabalho pela eleição/construção de um problema rigorosamente definido, seguida da proposta de uma conjectura (uma teoria explicativa) que o resolva. Essa teoria (explicação provisória) passa a ser imediatamente objeto de testes de falseamento (ou refutação), ou seja, testes que, contextualizados àquele problema específico, irão corroborá-la ou falseá-la, preferencialmente através da observação e experimentação (é aqui que o método hipotético-dedutivo faz aliança com o lógico-experimental). Uma vez substituída por uma teoria melhor (no sentido de ter maior conteúdo empírico e mais informação), a nova teoria também passa a se submeter ao teste da refutação. 
Depois que uma hipótese é proposta e testada, comprovando seu valor, não se pode permitir que seja abandonada sem uma "boa razão". A "boa razão" pode ser, por exemplo, a substituição da hipótese, por outra que possa ser mais bem testada, ou a refutação de uma das consequências da hipótese (Popper, 2010, p. 138).

Popper nos permite inferir que toda ciência é conjectural até que seja submetida a testagens. Se a teoria passa pelo teste, é ciência empírica, se não passa, é ciência conjectural. Daí sua colocação de que a Psicanálise é uma metafísica porque ela nem sequer pode ser submetida à testagem. Para ele, os sistemas metafísicos não são científicos porque seus argumentos não passam pelo critério de refutabilidade: "o critério que define o status científico de uma teoria é sua capacidade de ser refutada ou testada" (Popper, 1994, p. 66). Que o método hipotético-dedutivo aliado ao lógico-experimental seja hegemônico, no sentido de "dominante", ou até, paradigmático, isso não o coloca como o único método científico válido e capaz de produzir verdades. Nossa proposta é de que não existe apenas um método científico válido e de que, portanto, não existe apenas uma ciência (a do método que, dominando as práticas científicas contemporâneas, parece ser a única que merece ser chamada como tal). Mas, sim, que há vários métodos, igualmente válidos, igualmente científicos.

Para isso, precisamos justificar, inicialmente, porque é possível dizer que existem as ciências, em vez de somente "a" ciência (hipotéticodedutiva e lógico-experimental). Acompanhemos, então, A. Badiou (1996), na discussão que ele faz sobre o sistema matemático formal, de Zermelo-Fraenkel, na Terceira meditação de sua obra principal, "O Ser e o evento".

Primeiramente lembremos como o ser e o Um, cuja reciprocidade inaugura o discurso filosófico, são tratados pelo autor. Diante do impasse lógico gerado ainda nos pré-socráticos quanto ao que se apresenta - impasse de dizer se o que se apresenta é múltiplo ou é essencialmente um - Badiou decide por assumir que o Um não é, e que o ser se apresenta como múltiplo.

O ser não é o Um e não é qualquer número, uma vez que contar é da ordem da representação enquanto que o ser é da ordem da apresentação. "O que é preciso enunciar é que o um, que não é, existe somente como operação" (Badiou, 1996, p. 29). Dizer que o ser se apresenta como múltiplo, é também uma operação que fazemos. E o fazemos porque há uma impossibilidade de nos havermos com o ser mesmo, em sua real apresentação. Então o contamos (esta sala, esta imagem que contemplo, esta sinfonia que ouço, esta cidade etc.). 
A dupla tarefa de responder aos efeitos reais dos paradoxos presentes no pensamento do matemático G. Cantor, já no século $X X$, reunidos em sua constatação de que "o ponto de ser absoluto do múltiplo não é sua consistência (...) mas sua inconsistência" (Badiou, 1996, p. 43); tal tarefa - nos diz o filósofo - implicava aceitar que "nem a intuição nem a linguagem estão em condições de sustentar que o múltiplo puro (...) seja contado por um, num conceito unívoco" e implicava "proibir as multiplicidades paradoxais, isto é, o nãoser, cuja inconsistência ontológica tem por signo a destruição da linguagem" (Badiou, 1996, p. 43-44).

Responder àquela tarefa, segundo Badiou, foi um trabalho que se realizou entre 1908 e 1940, através de Ernest Zermelo, A. Fraenkel, von Neumann e Gödel. O sistema axiomático formal (sistema ZF) proposto por Zermelo e aperfeiçoado pelos que o seguiram, tem como primeira grande característica fixar o uso da relação de pertença $\left({ }^{€}\right)$ excluindo o sentido usual da expressão "ser um conjunto": "O um é atribuído unicamente ao símbolo ${ }^{€}$, isto é, ao operador da denotação da relação entre "alguma coisa" em geral e o múltiplo", (Badiou, 1996, p. 44). A segunda característica do sistema é que só há um tipo de apresentação do ser: o múltiplo. E a terceira característica é que "Zermelo subordina a indução de um múltiplo pela linguagem à existência, anterior a essa indução, de um múltiplo inicial" (Badiou, 1996, p. 45).

Da segunda característica do sistema importa-nos destacar uma inferência: "A teoria dos conjuntos revela que todo múltiplo é intrinsecamente múltiplo de múltiplos" (Badiou, 1996, p. 45). Pois, o que temos aqui, é uma colocação de ênfase não mais no ser (que, afinal, não é Uno - como demonstrado na Primeira Meditação do livro que estamos, aqui, acompanhando) nem num ente (que é impossível de ser distinguido, senão pelo pertencimento a um próprio múltiplo). A ênfase agora recai é sobre as relações de conjunto, pelo que de intrínseco se estabelece entre eles. Apliquemos esses princípios ao conjunto das ciências.

Os resultados das pesquisas do conjunto das ciências, no estado da situação em que hoje ele se encontra, com suas diversas áreas e disciplinas, formam uma "enciclopédia", termo que no léxico lógico do filósofo, significa "uma classificação das partes da situação que são discernidas por uma propriedade explicitável da língua da situação" (Badiou, 1996, p. 389) ${ }^{3}$. Assim, aos olhos de Badiou, e lembrando que uma situação é um estado de coisas, pode haver uma enciclopédia das ciências, bem como uma enciclopédia das artes, da política, enfim, pode haver enciclopédias sobre qualquer campo de saber. Porém, o autor ressalta que uma enciclopédia não está do lado da verdade, já que esta requer o vazio do não-saber, mas sim do lado da veridicidade. "O discernível é verídico. Mas somente o indiscernível é verdadeiro" (Badiou, 1996, p. 268). 
Considerando que: a) uma situação é "toda multiplicidade consistente apresentada" 4 (Badiou, 1996, p. 399), b) uma enciclopédia é um sistema geral dos saberes predicativos internos a uma situação (um estado de coisas que pode ser 1 ) científico, 2) artístico, 3) amoroso... etc.); e considerando que, c) a enciclopédia das ciências é um sistema geral dos saberes particulares internos à sua situação - ou seja, internos à situação das ciências; propomos que: a enciclopédia das ciências é um conjunto e uma multiplicidade consistente que se desdobra em outras multiplicidades, ou seja, em várias ciências, cada uma delas, um conjunto particular (sendo, pois, a Psicanálise, mais um desses conjuntos). E ainda: sendo o conjunto das ciências, uma multiplicidade consistente, cada uma das ciências que compõem tal conjunto, implicará, por sua vez, em novas multiplicidades (suas divisões de abordagem e de campos de atuação, bem como suas especializações). Pois, aprendemos com o filósofo que "tudo é múltiplo, tudo é conjunto" (Badiou, 1996, p. 45).

Pensamos que a Psicanálise encontra seu lugar na enciclopédia das ciências porque ela também se constitui como uma, embora, com particularidades bem específicas que a diferenciam das outras. 0 reconhecimento de que os termos dados pelo saber não recobrem toda a verdade de uma situação, o modo como ela considera e aborda a verdade, suas teorias sobre o psiquismo e sobre os grupos, seu modo de intervenção naquilo em que se detém, e seu método de verificação do que se produziu numa análise, são distintos de quaisquer outras teorias e métodos produzidos pelas outras ciências.

\section{A Ciência da Psicanálise em Freud e em Lacan: alguns apontamentos}

O próprio S. Freud referiu-se à Psicanálise como uma ciência, em mais de uma ocasião (1913/1987; 1915/1987; 1926/1987; $1927 / 1987 ; \quad 1933[1932] / 1987 ; 1940[1938] / 1987)$. Às vezes explicitamente. "A Psicanálise é, por certo, bem particularmente, unilateral, por ser a ciência do inconsciente mental" (Freud, 1926/ 1987 , p. 262). Outras vezes, de forma implícita, como nos textos em que discutiu de modo geral as teorias cientificas, incluindo nelas a Psicanálise. (1913/1987; 1915/1987; 1927/1987).

Sobre tê-la nomeado como "ciência do inconsciente mental" cabe uma consideração. Pensamos que com o uso do termo "mental" Freud estava mostrando sua intenção de que a Psicanálise fosse assimilada pela Universidade, uma vez que o mentalismo já era uma corrente fundamental na chamada Psicologia científica. Psicologia esta, que foi iniciada por Wilhelm Wundt em 1888 (Wundt, lembremos, propunha que os psicólogos estudassem o pensamento consciente por meio da introspecção). 
Não há propriamente uma teoria acabada da ciência em Freud, mas há reflexões importantes, como na Conferência XXXV, "A questão de uma weltanschauung", palavra que Freud traduziu para o inglês, aproximadamente, como uma construção intelectual baseada numa hipótese dominante capaz de solucionar todos os problemas da nossa existência.

Naquele texto, Freud nomeia a Psicanálise como ciência: "Na qualidade de ciência especializada (...), ela é praticamente incapaz de construir por si mesma uma weltanschauung: tem de aceitar uma weltanschauung científica" (Freud, 1933[1932]/1987, p. 194). Em seguida ele diz que o pensamento científico, logo, também o psicanalítico, visa a verdade: "O pensar científico (...) é no sentido de chegar à correspondência com a realidade (...). A essa correspondência com o mundo externo real chamamos de 'verdade'" (Freud, 1933[1932]/1987, p. 207). Ao final do texto, e aqui está a sabedoria de Freud, ele assinala que a visão cientifica do mundo tem limites: a weltanschauung científica "dificilmente merece um nome tão grandiloquente, pois não é capaz de abranger tudo, é muito incompleta e não pretende ser auto-suficiente e construir sistemas." (Freud, 1933[1932]/1987, p. 220).

O tema da verdade será retomado de forma mais aprofundada trinta e dois anos depois por J. Lacan na aula de abertura do Seminário "O objeto da Psicanálise", mais tarde publicado sob o titulo "A ciência e a verdade" (Lacan, 1966/1998). Nele Lacan diz que a verdade é o que fala, e que tendo como causa o ser de quem fala deixará de interessar às ciências modernas, por que elas ocultam de si sua divisão constitutiva entre ser e pensar. Assim, deixaria de existir no discurso cientifico o que não seria da ordem do pensar, ou seja, o que estivesse na ordem do ser de cada um. Este é o ponto em que, para o autor, por um lado, a Psicanálise se diferencia da ciência (referiase apenas à ciência lógico-experimental, em nosso entendimento), já que a Psicanálise investigará cada um em seu ser, naquilo que ele tem de indiscernível, naquilo que o diferencia dos demais e que não serve às praticas cientificas tradicionais de padronização e generalização. Paradoxalmente, aquele ponto citado, é o ponto em que, para Lacan (1966/1998), Psicanálise e ciência, de algum modo, convergem, pois é ali que o sujeito, sobre o qual se opera em Psicanálise, "só pode ser o sujeito da ciência" (p. 873).

Por que dizemos que Freud e Lacan insistiram em que a Psicanálise estava no conjunto das ciências? Já mencionamos a pretensão freudiana de que a Psicanálise fosse assimilada pela Universidade. Além disto, sabemos da sólida formação científica de Freud. Ele estudou com nomes importantes da pesquisa médica de seu tempo: Carl Claus, divulgador de Darwin em língua alemã; o eminente fisiologista Ernst Brucke, e com Hermann Helmoltz - "o homem da Renascença do século XIX" (Gay, 1989, p. 48). Precisava, pois, 
tornar a Psicanálise aceitável pelos pesquisadores que trabalhavam com o modelo da ciência dominante, em vigor naquela época. Ele se autorizou e insistiu até o final de sua vida, em chamar a Psicanálise de ciência: "a Psicanálise constitui uma parte da ciência mental da Psicologia." (Freud, 1940[1938]/1987, p. 316). Escreveu isto, um ano antes de seu falecimento.

Lacan, por seu turno, dialogou permanentemente com as ciências e adotou posições diferentes (mas não mutuamente excludentes) sobre a cientificidade da Psicanálise. $O$ fato de Lacan ter afirmado ao fim de seu ensino que a Psicanálise não é uma ciência ("Não é mesmo uma ciência de jeito nenhum." - Lacan, 1977-1978, citado por Santos, 2013, p. 354), não apenas precisa ser meditado (com quem, ou, com qual tradição Lacan dialogava nesse instante?), como também não invalida, não anula sua posição das décadas de 1950 e 1960 - período em que ele a incluiu no conjunto das ciências e no qual, situemos, começou a desenvolver o registro do simbólico. Pois, que uma verdade, descoberta ou enunciada por um autor num tempo específico de suas investigações (no caso, o Lacan das décadas de 50 e 60), seja depois abandonada ou mesmo recusada por ele, isso não retira daquela verdade, o que "havia" ali, de verdadeiro. Ele pode, simplesmente, e por qualquer razão, ter se dedicado a explorar outras vertentes de seu próprio pensamento.

Quanto ao período em que, para ele, a Psicanálise é uma ciência, observemos, inicialmente, suas considerações sobre o assunto em três de seus escritos produzidos no espaço de pouco mais de uma década: "Função e campo da fala e da linguagem em Psicanálise" (1953/1998), "Situação da Psicanálise e formação do psicanalista em 1956" (1956/1998), e "A ciência e a verdade" (1966/1998). Sobre esses textos, podemos resumir as posições do autor com as seguintes proposições, imediatamente acompanhadas dos escritos do próprio Lacan:

$1^{a}$ ) As ciências não são apenas as ciências experimentais ou exatas. "É impossível não centrar numa teoria geral do símbolo, uma nova classificação das ciências em que as ciências do homem retomem seu lugar central" (Lacan, 1953/1998, p. 286).

$2^{a}$ ) Lacan preferirá a expressão "ciências conjecturais", àquela que diz "ciências humanas": "É conhecida minha repugnância de sempre pela denominação 'ciências humanas', que me parece ser a própria voz da servidão" (Lacan, 1966/1998, p. 873).

$3^{a}$ ) Pois houve uma degradação: "uma noção de ciência verdadeira (...) se degradou, como se sabe, na inversão positivista que, colocando as ciências do homem no coroamento do edifício das ciências experimentais, na verdade as subordinou a estas". (Lacan, 1953/1998, p. 285). 
$4^{a}$ ) E pior que tal degradação, a ciência moderna (positivista, experimental, exata) passou a se pretender absoluta, ou hegemônica: "a epistemologia (...) não explicou plenamente (...) a mutação decisiva que, por intermédio da física, fundou $A$ ciência no sentido moderno, sentido que se postula como absoluto" (Lacan, 1966/1998, p. 869).

$5^{\text {a) }}$ Mas esse absolutismo pretendido tem algo de equivocado, de equivocante, e de enganoso também, pois a diferença entre a ciência moderna (no que ela tem de "exata") e as ciências conjecturais, não se sustenta:

já não parece aceitável a oposição que se traçaria entre as ciências exatas e aquelas para as quais não há porque declinar da denominação de conjecturais, por falta de fundamento para essa oposição. Pois a exatidão se distingue da verdade, e a conjectura não impede o rigor. $E$, se a ciência experimental herda das matemáticas sua exatidão, nem por isso sua relação com a natureza é menos problemática. (...) nossa física é apenas uma fabricação mental cujo instrumento é o símbolo matemático. (Lacan, 1953/1998, p. 287).

6a) A Psicanálise é, em Lacan, uma ciência conjectural.

Exercendo-se a técnica da Psicanálise na relação do sujeito com o significante, o que ela conquistou de conhecimentos só é situável ao se ordenar ao seu redor. Isso lhe confere seu lugar no grupo que se afirma como ordem das ciências conjecturais. (Lacan, 1956/1998, p. 475).

7a) A Psicanálise está no cerne de um movimento que deve instaurar "uma nova ordem das ciências" (expressão de Lacan): "Essa nova ordem não significa nada além de um retorno a uma noção de ciência verdadeira que já tem seus títulos inscritos numa tradição que parte do Teeteto" (Lacan, 1953/1998, p. 285).

E quanto ao posicionamento final de Lacan, em que pudemos lêlo recusando a cientificidade da Psicanálise, façamos uma breve observação.

Quando no Seminário 24, Lacan diz que a Psicanálise não é uma ciência, ele o fez, naquele momento, em resposta a um autor específico: "a Psicanálise é para ser levada a sério, apesar de que não é uma ciência (...) como mostrou superabundantemente 0 assim chamado Karl Popper" (Lacan, 1977-1978, p. 9, citado por Santos \& Lopes, 2013, p. 354). Vimos que Popper distinguia a ciência empírica dos sistemas metafísicos, ou pseudociências (nas quais incluía a Psicanálise). Popper não foi o único a tematizar o que é ou não científico, e suas posições, certamente muito bem 
argumentadas e elaboradas, não precisam ser tomadas como as palavras definitivamente finais, sobre o assunto.

E ainda sobre o seminário 24 , não se pode dizer que Lacan tenha cedido, ali, terminantemente diante de Popper, já que, no mesmo seminário, ele manifestou a esperança de que a Psicanálise viesse algum dia, a portar uma cientificidade: "Ela não tem seu estatuto como ciência e não pode senão aguardá-lo, esperá-lo." (Lacan, 19771978 , p.52, citado por Santos \& Lopes, 2013, p. 353).

Pensamos que o estatuto esperado por Lacan, depende de uma formalização do saber e da práxis psicanalítica. Formalização reclamada já em 1953, ano no qual, referindo-se ao papel da Psicanálise na direção da subjetividade moderna, ele escreveu: "é esse o problema dos fundamentos que devem assegurar à nossa disciplina seu lugar nas ciências: problema de formalização, na verdade muito mal introduzido." (Lacan, 1953/1998, p. 285). E mais adiante, no mesmo texto: "Ela [a Psicanálise] só dará fundamentos científicos à sua teoria e à sua técnica ao formalizar adequadamente as dimensões essenciais de sua experiência" (p. 290).

Em que sentido devemos pensar o termo "fundamento"? Com Houaiss (2012), chamaremos de fundamento (cuja raiz etimológica, fundamentum, significa "alicerce"), o "conjunto de princípios a partir dos quais se pode (...) deduzir um sistema, um agrupamento de conhecimentos" (Houaiss). E avançando um pouco mais, consideraremos que os termos "conjunto", "princípios", "deduzir" e "conhecimentos", surgidos nessa definição, nos levarão a tratar o termo e a ideia que ele expressa, na acepção de "qualquer coisa real (de um enunciado ou conjunto de enunciados)" (Ferrater Mora, 1978 , p. 117); e não na acepção de causa enquanto "conceito ontológico que expressa a necessidade do ser enquanto substância" (Abbagnano, 2007, p. 475).

Assim, "fundamento", para nós, não é substância ou essência como em Hegel, para o qual, "o fundamento é a essência que é em si, e esta é essencialmente fundamento" (Hegel, 1827, § 121, citado por Abbagnano, 2007, p. 475). Fundamento não é um "em si" substantivo, e aqui será entendido como um conjunto de princípios que, se relacionando, permitem deduzir um sistema teórico, baseado numa prática clínica. Conjunto de princípios que está disposto na obra de S. Freud, de cujo trabalho clínico e teórico, deduziram-se outras práticas em Psicanálise, das quais nos interessa, também, o legado de Jacques Lacan, psicanalista que soube compreender o texto freudiano, e soube fazê-lo avançar à medida que evoluía o século XX.

\section{Verdades na Psicanálise}


Se a ciência hegemônica do método lógico-experimental, com a qual Lacan dialogou desde a década de 1950, não quer saber da verdade ("da verdade como causa, ela não quer-saber-de-nada" - Lacan, $1966 / 1998$, p. 889), o mesmo não se pode dizer do procedimento psicanalítico. Pois rigorosamente falando, cada um que se põe em análise, convoca-se e ao seu analista, à criação de um novo procedimento de verdade. Ao falar em análise, cada um se remete às singularidades de coisas que só ele experimentou e experimenta e que, pelo sofrimento de seus sintomas, demanda de ambos (analista e analisando), a descoberta de uma nova verdade.

Desse modo, faz sentido dizer, como outros autores, que a Psicanálise recomeça sempre a cada novo paciente que ocupa o divã. Assim como hoje, cada sujeito que Freud atendeu, funcionou para ele como uma exigência de trabalho convocando-o a investigar a verdade do que ali causava sofrimento, diferentemente do que já estava estabelecido por outros saberes. Em extensão, Freud deduziu, logicamente, consequências teóricas sobre a histeria e sobre outras formas de sofrimento psíquico.

O que estamos dizendo, e que já ocorre nos consultórios dos psicanalistas é que, para que uma análise se produza, há que acontecer nesse encontro do analista com seu analisando, algo da ordem de um evento 5 . Ou o procedimento analítico não se caracterizará como um procedimento genérico.

O procedimento genérico é o que permite a produção de uma verdade não pertencente ao domínio do saber já estabelecido, posto que tal procedimento (referente do trio evento-intervenção-operador de fidelidade) requer o vazio, o não-sabido em uma situação (uma situação é "um estado de coisas"). E ele o faz pela evitação de um determinante do saber já estabelecido, ou seja, pela evitação de uma parte da situação "composta de termos que têm em comum uma propriedade explicitável, na língua da situação" (Badiou, 1996, p. 389).

Toda parte nomeável, discernida e classificada pelo saber, remete não ao ser em situação como tal, mas ao que a língua recorta nele de particularidades detectáveis. O procedimento fiel, precisamente por se originar de um evento em que o vazio é convocado, e não da relação estabelecida da língua com o estado, dispõe em seus estados infinitos, do ser da situação. Ele é uma-verdade da situação ao passo que um determinante do saber não especifica mais do que veridicidades (Badiou, 1996, p. 268).

Com a intervenção do analista, possibilita-se que uma verdade emerja e se desdobre num novo universo ao qual o paciente poderá (ou não) permanecer fiel. Uma fidelidade "é o conjunto 
dos procedimentos pelos quais discernimos, numa situação, os múltiplos (...) de um múltiplo eventural" (Badiou, 1996, p. 188). Ela depende de um evento, reagrupa os múltiplos marcados pelo evento permitindo ver, provisoriamente, quais são conexos e quais são desconexos com o evento, e, por último, opera na situação em que se deu o evento, podendo aparecer como um contra-estado ou como um subestado da própria situação (conforme o expõe Badiou na Meditação 23 de "O ser e o evento").

Trabalhando com cada ente humano no que lhe é particular (sua estrutura psíquica, seu modo de gozo neurótico, psicótico ou perverso) e incluindo em sua práxis, o vazio do não saber (requisito dos procedimentos de verdade), a Psicanálise aponta para cada um, a cada análise, uma verdade. O que se espera ao final de um processo analítico é que o analisando reconheça e decida sobre o que nele há de único e paradoxal ("há" se diz em Badiou como "capacidade participativa" e como "chave de uma operação" - conforme se lê em "O ser e o evento", p. 39). Reconheça o que há, mais além de sua estrutura, e que consiste em seu modo inconsciente e singular de desejar e gozar em sua vida.

Essa verdade reconhecida, ainda que logo depois repertoriada num novo significante e tornada, assim, um saber (campo das veridicidades), ela implicará numa mudança de posição subjetiva. Algo novo se dará. Pois numa análise, como em outras situações, um evento (também traduzido do francês "événement", como "acontecimento") implica num enunciado, o qual opera uma mudança radical do valor do Real envolvido naquele mesmo acontecimento. Pois vejamos:

Chamaremos épsilon o enunciado acontecimental. Em virtude da regra lógica da separação, percebe-se que a abolição do acontecimento, cujo ser inteiro está em desaparecer, deixa subsistir o enunciado acontecimental épsilon, que o acontecimento implica, como sendo ao mesmo tempo um real da situação (pois ela já estava aí), mas tomado numa mudança radical de valor, já que ele era indecidível e foi decidido (Badiou, 2008, p. 46).

Contudo, talvez o mais importante no contexto das diferenças entre as ciências, ou seja, o que torna a Psicanálise uma ciência tão particular e distinta das outras, é que ela admite haver um resto inassimilável em seu discurso, ao final de seus procedimentos. Pois, com o último ensino de Lacan, "incorpora-se ao fazer clinico do analista a convicção de que haverá sempre restos sintomáticos porque é da natureza do gozo resistir ao sentido. Há um gozo impregnado no corpo e que se produz no corpo" (Santiago, 2011, p. 8). 
A Psicanálise sustenta com o sujeito, isso que não se deixa atingir por uma luz definitiva (e nem mesmo por uma câmera que o registre como luz ou como sombra), sem querer esgotá-lo ou recobri-lo com significantes do tipo "a palavra final". Mas, ao apontar umaverdade, e não " $A$ " verdade, ela também produz um novo para esse sujeito, fazendo-o mudar de posição em relação a seus sintomas e possibilitando que ele encontre um jeito próprio e inédito, de lidar com o que não muda. Refiro-mo-nos aqui ao real do sinthoma de cada um, sinthoma sobre o qual Lacan discorreu em seu seminário 23 (Lacan, 2007), o qual compõe com os seminários seguintes, o que se convencionou chamar de "o último ensino de Lacan", ou seja, seu aprofundamento teórico e sua ênfase maior no registro do real (Souza Leite, 2000), com a consequente indicação de que uma análise deve se orientar pelo que deste registro está em jogo no psiquismo do analisante.

O desafio posto para todos que se nomeiam psicanalistas ou praticantes da Psicanálise, é o de formalizar cientificamente sua prática. Um modo, dentre outros, de formalização de uma ciência, pode ser o de construir um dispositivo através do qual se constate a veridicidade do que o procedimento científico revelou de verdadeiro. No caso da Psicanálise, o "passe", anunciado por Lacan na "Proposição de 9 de outubro de 1967 sobre o psicanalista da Escola" (Lacan, 1968/2003), talvez seja um dispositivo de formalização do tipo que estamos procurando, posto que nele, se faz representar o que de mais específico uma Psicanálise produz: singularidades.

Enfim, nossa hipótese de trabalho (a Psicanálise é uma ciência particular do singular) pode ser entendida, simplesmente, como uma retomada de uma aposta de Lacan, pronunciada diversas vezes em seu ensino das décadas de 1950 e 1960, e como uma investigação que visa dar continuidade a um desejo permanente de Freud, de ver reconhecida a cientificidade da Psicanálise. Desejo que, como vimos, ele o manifestou até o final de sua vida.

\section{Referências}

Abbagnano, N. (1998). Dicionário de filosofia. (2a ed.). São Paulo: Martins Fontes.

Abbagnano, N. (2007). Dicionário de filosofia. (5a ed.). São Paulo: Martins Fontes.

Ajuriaguerra, J. (1983). Tratado de Psiquiatria Infantil. Rio de Janeiro: Masson.

Badiou, A. (1991). Manifesto pela filosofia. Rio de Janeiro: d'aoutra.

Badiou, A. O Ser e o Evento. (1996). Rio de Janeiro: Jorge Zahar Editor / Ed. UFRJ. 
Badiou, A. (2008). Oito teses sobre o universal. Recuperado em 28 fev, 2014, de http://estudosbadiouianos.files.wordpress.com/ 2012/12/badiou-oito-teses-sobre-o-universal.pdf

Brousse, M. H. (2013). Ressonâncias do VIII Congresso da AMP. Curinga, 1(3), 67-74.

Chesnais, F. (2002). A teoria do regime de acumulação financeirizado: conteúdo, alcance e interrogações. Economia e Sociedade, 11(18), 1-44. Recuperado em 12 março, 2014, de http://www.eco.unicamp.br/docdownload/publicacoes/instituto/ revistas/economia-e-sociedade/V11-F1-S18/01-Chesnais.pdf? origin=publication_detail

Cunha, M. O. (2004). Lógica, lógicas: uma visão panorâmica. Recuperado em 14 junho, 2013, de http://www.uff.br/ dalicenca/images/stories/caderno/volume5/Igica_lgicas.pdf

Demo, P. (2011). Praticar ciência: metodologia do conhecimento científico. São Paulo: Saraiva.

Ey, H., Bernard, P., \& Brisset, C. (1988). Manual de Psiquiatria. (5a ed.). Rio de Janeiro: Masson do Brasil.

Ferrater Mora, J. (1978). Fundamento. In Dicionário de filosofia. Lisboa: Dom Quixote.

Ferrater Mora, J. (1994). Indivíduo. In Diccionario de Filosofía. Barcelona: Ariel.

Focchi, M. (2011). Le nombre dans la science et dans La psychanalyse. Mental - Revue Internationale de Psychanalyse, (25), 89-103.

França Neto, O. (2009). Por uma nova concepção de universal, 12(4), Recuperado em 25 fevereiro, 2014, de http:// www.scielo.br/scielo.php?script=sci_arttext\&pid=S141547142009000400003\&lng=pt\&nrm=iso\&tlng=pt

Freud, S. (1987) O interesse científico da Psicanálise. In Edição Standard Brasileira das Obras Completas de Sigmund Freud. (J. Salomão, trad., Vol. 13, pp. 199-226). Rio de Janeiro: Imago. (Trabalho original publicado em 1913).

Freud, S. (1987) Os instintos e suas vicissitudes. In Edição Standard Brasileira das Obras Completas de Sigmund Freud. (J. Salomão, trad., Vol. 14, pp. 129-162). Rio de Janeiro: Imago. (Trabalho original publicado em 1915).

Freud, S. (1987) A questão da análise leiga. In Edição Standard Brasileira das Obras Completas de Sigmund Freud. (J. Salomão, trad., Vol. 20, pp. 205-293). Rio de Janeiro: Imago. (Trabalho original publicado em 1926).

Freud, S. (1987) O futuro de uma ilusão. In Edição Standard Brasileira das Obras Completas de Sigmund Freud. (J. Salomão, trad., Vol. 21, pp. 13-71). Rio de Janeiro: Imago. (Trabalho original publicado em 1927). 
Freud, S. (1987) A questão de uma Weltanschaunng. In Edição Standard Brasileira das Obras Completas de Sigmund Freud. (J. Salomão, trad., Vol. 22, pp. 193-220). Rio de Janeiro: Imago. (Trabalho original publicado em 1933[1932]).

Freud, S. (1987) Algumas lições elementares da Psicanálise. In Edição Standard Brasileira das Obras Completas de Sigmund Freud. (J. Salomão, trad., Vol. 23, pp. 314-321). Rio de Janeiro: Imago. (Trabalho original publicado em 1940[1938]).

Gay, P. (1989). Freud: Uma vida para o nosso tempo. São Paulo: Cia. das Letras.

Haack, S. (2002). Filosofia das lógicas. São Paulo: Editora UNESP.

Houaiss, A. (2012). Fundamento. In Grande Dicionário Houaiss Beta da Língua Portuguesa. Recuperado em 11 de abril de 2014, de http://houaiss.uol.com.br/busca?palavra=fundamento

Iannini, G. (2007). Psicanálise: ciência êxtima. Epistemo-somática. 4(1), 69-78. Recuperado em 1 Ago, 2013, de http:// pepsic.bvsalud.org/scielo.php?script=sci_arttext\&pid=S198020052007000100007\&lng=pt\&nrm=iso\&tlng=pt

Lacan. J. (1998). Situação da Psicanálise e formação do psicanalista em 1956. In Escritos. Rio de Janeiro: Jorge Zahar. (Trabalho original publicado em 1956).

Lacan. J. (1998). Função e campo da fala e da linguagem em Psicanálise. In Escritos. Rio de Janeiro: Jorge Zahar. (Trabalho original publicado em 1953).

Lacan. J. (1998). A ciência e a verdade. In: Escritos. Rio de Janeiro: Jorge Zahar. (Trabalho original publicado em 1966).

Lacan. J. (2003). Proposição de 9 de outubro de 1967 sobre o psicanalista da Escola. In Outros Escritos. Rio de Janeiro: Jorge Zahar. (Trabalho original publicado em 1968).

Lacan. J. (2007). O Seminário. Livro 23: O sinthoma. Rio de Janeiro: Jorge Zahar.

Lalande, A. (1993). Particular. In Vocabulário Técnico e Crítico da Filosofia. São Paulo: Martins Fontes.

Lalande, A. (s/d). Singular. In Vocabulário Técnico e Crítico da Filosofia. Porto: Rés.

Milner, J. C. (1996). A Obra Clara: Lacan, a ciência, a filosofia. Rio de Janeiro: Jorge Zahar.

Popper, K. S. (1994). Conjecturas e Refutações. (3a ed.). Brasília: Editora da Universidade de Brasília.

Popper, K. S. (2010). O método científico. In Textos Escolhidos/ Karl Popper. Rio de Janeiro: Contraponto/PUC-Rio.

Sadock, B. J., \& Sadock, V. A. (2007). Compêndio de Psiquiatria: Ciência do comportamento e psiquiatria clínica. (9a ed.). Porto Alegre: Artmed.

Santiago, J. (2011). O Sinthoma é Um. Reprografia. Universidade Federal de Minas Gerais. 
Santos, T. C., \& Lopes, R. G. (2013). Psicanálise Ciência e Discurso. Rio de Janeiro: Cia. de Freud.

Souza Leite, M. P. (2000). Psicanálise Lacaniana. São Paulo: Iluminuras.

\section{Endereço para correspondência Wanderley Magno de Carvalho}

Universidade Federal de Minas Gerais

Programa de Pós-Graduação em Psicologia da UFMG

Av. Antônio Carlos, 6627, Pampulha, CEP 31270-901, Belo Horizonte - MG, Brasil

Endereço eletrônico: wd.carvalho@uol.com.br

Recebido em: 06/05/2014

Aceito para publicação em: 31/10/2014

\section{Notas}

* Doutorando em Psicologia - UFMG - Belo Horizonte - Brasil. Mestre em Psicologia

- CES-JF. Especialista em Filosofia Contemporânea - FUNREI/UFSJ. Psicólogo FUNREI/UFS].

${ }^{1}$ Capital financeirizado é o "capital que se valoriza sob a forma de aplicação financeira e que provém do lucro das aplicações financeiras" (Chesnais, 2002). A valorização desse capital iniciou-se, segundo o autor, nos anos de 1980 nos países de capitalismo avançado, teve influências sobre a configuração de investimentos e a distribuição de renda naqueles países e deu a partida para um processo social também chamado de "regime de acumulação financeirizado" que adentrou a OMC e o FMI.

2 Uma investigação é, por definição, uma "sucessão finita de conexões, ou de nãoconexões, observadas no quadro de um procedimento de fidelidade, entre termos da situação e o nome do evento que a intervenção fez circular" (Badiou, 1996, p. 394).

3 E ainda: "Chamamos 'enciclopédia' o sistema geral dos saberes predicativos internos a uma situação, ou seja, o que todos sabemos sobre a política, sobre os sexos, sobre a cultura e a arte, sobre as técnicas e assim por diante" (Badiou, 2008, p. 45).

${ }^{4}$ A multiplicidade se divide em consistente e inconsistente. A multiplicidade consistente é a de composição, pois "múltiplo se diz também da composição da conta, isto é, o múltiplo como vários-uns" (Badiou, 1996, p. 30). A inconsistente é a da apresentação e da inércia.

5 Já mencionamos acima, alguns predicados de um evento. Acrescentemos aqui, uma formula escrita por Badiou: "Um evento de sítio eventural dado é o múltiplo composto, por um lado, dos elementos do sítio; por outro, de si mesmo (o evento)" (Badiou, 1996, p. 390). À qual acrescentamos: um sítio eventural é "um múltiplo em situação (...) se ele for totalmente singular: ele é apresentado, mas nenhum dos seus elementos o é. Pertence, mas está radicalmente não incluído. É elemento, mas não é, em absoluto, uma parte. É totalmente a-normal" (Badiou, 1996, p. 399). 